\title{
The Effect of Agoraphobia on Oxidative Stress in Panic Disorder
}

\author{
Isil Gogcegoz Gul ${ }^{\circledR}$, Rifat Karlidag², Birgul Elbozan $\mathrm{Cumurcu}^{2}$, Yusuf Turkoz ${ }^{3}$, \\ Sukru Kartalci ${ }^{2}$, A. Cemal Ozcan ${ }^{4}$, and M. Erman Erdemli ${ }^{3}$ \\ ${ }^{1}$ Uskudar University, Department of Psychiatry, Istanbul, Turkey \\ ${ }^{2}$ Inonu University Faculty of Medicine, Department of Psychiatry, Malatya, Turkey \\ ${ }^{3}$ Inonu University Faculty of Medicine, Department of Biochemistry, Malatya, Turkey \\ ${ }^{4}$ Inonu University Faculty of Medicine, Department of Neurology, Malatya, Turkey
}

\begin{abstract}
We aimed to investigate whether agoraphobia (A) in panic disorder (PD) has any effects on oxidative and anti-oxidative parameters. We measured total antioxidant capacity (TAC), paraoxonase (PON), arylesterase (ARE) antioxidant and malondialdehyde (MDA) oxidant levels using blood samples from a total of 31 PD patients with A, 22 PD patients without A and 53 control group subjects. There was a significant difference between the TAC, PON, ARE and MDA levels of the three groups consisting of PD with A, PD without A and the control group. The two-way comparison to clarify the group creating the difference showed that the TAC, PON, and ARE antioxidants were significantly lower in the PD with A group compared to the control group while the MDA oxidant was significantly higher. There was no significant difference between the PD without A and control groups for TAC, PON, ARE and MDA levels. We clearly demonstrated that the oxidative stress and damage to the anti-oxidative mechanism are significantly higher in the PD group with A. These findings suggest that oxidative/anti-oxidative mechanisms may play a more important role on the pathogenesis of PB with A.
\end{abstract}

Psychiatry Investig 2013;10:317-325

Key Words Agoraphobia, Free radical, Panic disorder, Oxidative stress, Total antioxidant capacity.

\section{INTRODUCTION}

Panic disorder (PD) is an anxiety disorder with a chronic course characterized by recurrent, unexpected panic attacks and a series of long-term signs and behaviors between the attacks. The panic attacks in this professionally and socially disabling disorder appear at a most unexpected time and location during the day and increase in severity to reach their peak within 10 minutes. ${ }^{1,2}$ The patients feel that they are confronted with a disaster during a panic attack. The fear of experiencing an attack (expectation anxiety) leads to avoidance of situations in which getting help or running away can be difficult such as crowds, being alone outside the home, or traveling, and patients endure these situations with intensive anxiety known as agoraphobia (A)., ${ }^{1,3,4}$

Received: December 1, 2012 Revised: February 17, 2013

Accepted: May 20, 2013 Available online: December 16, 2013

$\triangle$ Correspondence: Isil Gogcegoz Gul, MD

Uskudar University NP Istanbul Hospital, MD, Saray Mh., 34768 Umraniye, Istanbul, Turkey

Tel: +90 5332076230, Fax: +90 2164741256, E-mail: dr.isilggul@mynet

(a) This is an Open Access article distributed under the terms of the Creative Commons Attribution Non-Commercial License (http://creativecommons.org/licenses/bync/3.0) which permits unrestricted non-commercial use, distribution, and reproduction in any medium, provided the original work is properly cited.
The evidence on the important role played by free oxygen radicals on the pathophysiology of neuropsychiatric disorders has accumulated in recent years. ${ }^{5-10}$

Free radicals are molecules that appear as the natural result of normal metabolic pathways. The total amount of oxidants and antioxidants of a healthy organism are in balance. ${ }^{11,12}$ If the endogenous and exogenous oxidants that appear go above a certain level or the antioxidants become inadequate, the balance shifts toward the oxidants and oxidative stress appears. ${ }^{13,14}$ Free oxygen radicals at a higher than normal level damage proteins. Lipid, carbohydrates, nucleic acids and beneficial enzymes that are the building blocks of the organism and can cause permanent damage. A hyperactive oxidative metabolism can be the result of physiological stress, pathogens or inflammatory responses. Genetic variability and physiological factors can affect the oxidative defense capacities of the individual. These features may play a role in the disorder's pathogenesis, continuation of the symptoms and their recurrence. The defensive mechanisms of the cell prevent free radical formation, convert oxidant substances to less toxic products, distance free radicals from vital structures and repair molecular damage..$^{15,16}$

A study on the oxidative and anti-oxidative parameters in 
PD has measured the oxidant and antioxidant levels in PD patients and found higher levels than the control group. The same study found a positive relationship between disease severity and the oxidant and antioxidant levels. ${ }^{17}$ Another study has again evaluated oxidative and anti-oxidative parameters in PD. Oxidants were higher in the patient group than the control group in this study but there was no significant difference regarding antioxidant parameters. It has been stated in light of these findings that free oxygen radicals may play a role in PD pathogenesis and that they can be used as a biological marker of the disease. ${ }^{18}$

Many important findings have been revealed by studies on oxidative and anti-oxidative parameters related to PD etiology. ${ }^{17-20}$ However, it is interesting that any effect of $\mathrm{A}$, which accompanies $30-50 \%$ of PD cases, on oxidative and anti-oxidative parameters has not been studied. ${ }^{3}$ We supposed that oxidative stress and anti-oxidative parameters would increase with the addition of A to PD. To investigate this hyphothesis, we compared three groups consisting of a PD subgroup with A, PD subgroup without A and a control group, in terms of oxidative and anti-oxidative parameters. As far as we know, this is the first study to investigate oxidative and anti-oxidative parameters in the PD subtypes with and without A. This evaluation is important as it can act as a guide for future studies and shed light on research investigating the pathogenesis of the PD subtypes with and without A.

\section{METHODS}

\section{Subjects}

This study was conducted on a total of 53 PD patients (21 males, 32 females) and 53 age- and sex-matched control subjects (21 males, 32 females) presenting at the Inonu University Faculty of Medicine Psychiatry Outpatients Department and diagnosed according to the Diagnostic and Statistical Manual of Mental Disorders, fourth edition text-revision (DSM-IVTR) diagnostic scales.

The participants were informed on the procedure to be performed and their consent was obtained. The study project was approved by the Inonu University Faculty of Medicine Ethic Committee.

The diagnoses of the patients participating in the study were determined using a structured interview form arranged according to the criteria of DSM-IV-TR (The Structured Clinical Interview for Diagnostic and Statistical Manual of Mental Disorders, SCID-I). The exclusion criteria for the patient group were the presence of an education or language problem to the degree it would interfere with the diagnostic interview, a comorbid psychiatric disorder diagnosis, severe medical problem such as hypertension or diabetes, neurological disorders; severe physical disease, alcohol, smoking or substance abuse and dependence, pregnancy, and a history of drug treatment within the last three months while the exclusion criteria for the control group were a personal or family history of psychiatric disorder, severe medical problem such as hypertension or diabetes, alcohol, smoking or substance abuse or dependence, pregnancy and a history of drug treatment within the last three months.

The data collection tools were the Sociodemographic Data Form, the Panic and Agoraphobia Scale (PAS), Hamilton Depression Rating Scale (HDRS) and the Hamilton Anxiety Rating Scale (HARS).

\section{Biochemical analysis}

\section{Serum PON, ARE activity and TAC level analysis}

Serum PON activity, ARE activity and TAC ${ }^{21}$ levels were measured on the autoanalyzer (Microgenics; MGC-240) using Rel-Assay-Diagnostics brand commercial kits. Serum TAC levels were expressed as $\mu$ molTroloxEqv/L while PON and ARE activity levels were expressed as U/L.

\section{Serum MDA level analysis}

MDA, the most important indicator of lipid peroxidation, was analyzed by the method described by Ohkawa et al. ${ }^{22}$ The main principle of the analysis is the formation of a pinkcolored chromogen when the MDA present in the environment reacts following heating with thiobarbituric acid in an acidic environment. The intensity of the pink color directly correlates with the MDA concentration in the sample. Serum MDA levels have been expressed as $\mu \mathrm{mol} / \mathrm{L}$.

\section{Statistical analysis}

Statistical Package for the Social Sciences (SPSS) for Windows 16.0 software was used to analyze study data. Quantitative variables were expressed as mean \pm standard deviation (SD) while qualitative variables were expressed as numbers and percentages. A normal distribution was found for quantitative variables by using the Shapiro Wilk normalcy test ( $p>0.05)$. Comparison of the patient and control groups was the unpaired t-test, Pearson chi-square analysis and Fisher's Exact chi-Square test. The three-way comparison of the PD with A, PD without A and control groups for oxidative and anti-oxidative parameters was with the one-way variance analysis (ANOVA) test and the two-way comparison with the Bonferroni method. The intragroup variables were tested with the Pearson Correlation Analysis. The association between A and clinical variables (age, number of attacks, PAS, HDRS, HARS), oxidative stress parameter (MDA) and antioxidants (TAC, PON, ARE) was evaluated with the Multiple Linear Re- 
gression Analysis. A p value $<0.05$ was accepted as statistically significant.

\section{RESULTS}

A total of 53 patients consisting of 21 (39.6\%) males and 32 (60.4\%) females were included in the study. The mean age of the patients was $36.8 \pm 10.8$ years. The number of patients with $A$ was 31 and the mean age was $36.9 \pm 11.2$ years while the relevant numbers for the group without A were 22 and $36.7 \pm$ 10.5 years. The control group consisted of 53 healthy individuals, composed of 21 (39.6\%) males and 32 (60.4\%) females. The mean age of the controls was $36.9 \pm 10.8$ years. There was no difference between the patient and control groups for age and gender $(\mathrm{p}>0.05)$. There was also no difference between the PD groups with and without A for age and gender $(\mathrm{p}>0.05)$.
Comparison of the patient and control groups for oxidative and anti-oxidative stress parameters revealed significantly lower levels of TAC, PON and ARE levels in the two groups ( $\mathrm{p}=0.025, \mathrm{p}=0.001, \mathrm{p}=0.033$, respectively). MDA levels were significantly higher in the patient group than the control group $(\mathrm{p}=0.003)$. Table 1 presents the comparison of the patient and control groups for the oxidative stress parameter (MDA) and antioxidants (TAC, PON, ARE).

Comparison of the $\mathrm{PD}$ with and without $\mathrm{A}$ groups and the control group for TAC, PON, ARE and MDA showed that the TAC, PON, ARE antioxidants and MDA oxidant were statistically significantly different $(\mathrm{p}=0.004, \mathrm{p}=0.002, \mathrm{p}=0.019$, $\mathrm{p}=0.0001$, respectively). Two-way comparison for TAC, PON, ARE and MDA of the PD with A, PD without A and the control groups to determine the group that was creating the difference revealed a statistically significant difference between

Table 1. Comparison of the patient and control groups regarding the oxidative stress parameter (MDA) and antioxidants (TAC, PON, ARE)

\begin{tabular}{|c|c|c|c|c|}
\hline & Patient $(\mathrm{N}=53)$ & Control $(\mathrm{N}=53)$ & \multirow{2}{*}{$\mathrm{t}$} & \multirow{2}{*}{$\mathrm{p}$} \\
\hline & $($ Mean \pm SD $)$ & $($ Mean \pm SD $)$ & & \\
\hline TAC ( $\mu$ molTroloxEqv./L) & $1.71 \pm 0.20$ & $1.80 \pm 0.20$ & -2.276 & $0.02^{*}$ \\
\hline PON (U/L) & $67.85 \pm 47.17$ & $108.89 \pm 70.02$ & -3.538 & $0.001^{*}$ \\
\hline $\operatorname{ARE}(\mathrm{U} / \mathrm{L})$ & $93.64 \pm 8.19$ & $97.09 \pm 8.24$ & -2.162 & $0.03^{*}$ \\
\hline $\operatorname{MDA}(\mu \mathrm{mol} / \mathrm{L})$ & $2.62 \pm 0.90$ & $2.16 \pm 0.65$ & 3.042 & $0.003^{*}$ \\
\hline
\end{tabular}

The results have been expressed as mean \pm standard deviation. ${ }^{*} \mathrm{p}<0.05$. TAC: total antioxidant capacity, PON: paraoxonase, ARE: arylesterase, MDA: malondialdehyde

Table 2. Comparison of the PD with and without $A$ and control groups regarding the oxidative stress parameter (MDA) and antioxidants (TAC, PON, ARE)

\begin{tabular}{|c|c|c|c|c|c|}
\hline & $\mathrm{PD}$ with $\mathrm{A}(\mathrm{N}=31)$ & PD without $A(N=22)$ & Control $(\mathrm{N}=53)$ & & \\
\hline & $(\mathrm{Mean} \pm \mathrm{SD})$ & $($ Mean $\pm S D)$ & $(\mathrm{Mean} \pm \mathrm{SD})$ & 1 & $\mathrm{p}$ \\
\hline \multirow[t]{4}{*}{ TAC ( $\mu$ molTroloxEqv/L) } & $1.65 \pm 0.21$ & $1.80 \pm 0.17$ & $1.80 \pm 0.20$ & 5.876 & $0.004^{*}$ \\
\hline & & & & & $0.041^{\dagger}$ \\
\hline & & & & & $0.004^{\ddagger}$ \\
\hline & & & & & $1.000^{\S}$ \\
\hline \multirow[t]{4}{*}{$\mathrm{PON}(\mathrm{U} / \mathrm{L})$} & $60.71 \pm 45.56$ & $77.91 \pm 48.60$ & $108.89 \pm 70.02$ & 6.799 & $0.002^{*}$ \\
\hline & & & & & $0.911^{\dagger}$ \\
\hline & & & & & $0.002^{\ddagger}$ \\
\hline & & & & & $0.130^{\S}$ \\
\hline \multirow[t]{4}{*}{$\operatorname{ARE}(\mathrm{U} / \mathrm{L})$} & $91.90 \pm 8.19$ & $96.09 \pm 7.71$ & $97.09 \pm 8.24$ & 4.099 & $0.019^{*}$ \\
\hline & & & & & $0.202^{\dagger}$ \\
\hline & & & & & $0.017 \ddagger$ \\
\hline & & & & & $1.000^{\S}$ \\
\hline \multirow[t]{4}{*}{$\mathrm{MDA}(\mu \mathrm{mol} / \mathrm{L})$} & $3.00 \pm 0.98$ & $2.08 \pm 0.34$ & $2.16 \pm 0.65$ & 15.941 & $0.0001^{*}$ \\
\hline & & & & & $0.0001^{\dagger}$ \\
\hline & & & & & $0.0001^{\ddagger}$ \\
\hline & & & & & $1.000^{\S}$ \\
\hline
\end{tabular}

The results have been provided as mean \pm standard deviation. *between the groups of PD with A, PD without A and the control subjects, ${ }^{\dagger} \mathrm{PD}$ with A vs. PD without A, $\neq$ PD with A vs. the control group, §PD without A vs. the control group. TAC: total antioxidant capacity, PON: paraoxonase, ARE: arylesterase, MDA: malondialdehyde, PD: panic disorder 
the PD groups with and without $\mathrm{A}$ and between the $\mathrm{PD}$ with A and the control group for TAC ( $\mathrm{p}=0.041, \mathrm{p}=0.004$, respectively). There was no difference between the PD without $\mathrm{A}$ and control groups $(\mathrm{p}=1.00)$. There was also no significant difference for PON between the PD groups with and without $\mathrm{A}$ and between PD group without $\mathrm{A}$ and control group ( $\mathrm{p}=$ $0.91, p=0.13$, respectively) while there was a significant difference between the PD with A group and the control group ( $\mathrm{p}=$ 0.002). There was no significant difference for ARE between the PD groups with and without $A$ and between the PD group without $A$ and the control group $(p=0.202, p=1.00$, respectively) while there was a significant difference between the PD with A and control groups ( $\mathrm{p}=0.017)$. There was a significant difference for MDA between the PD groups with and without $\mathrm{A}$ and between the PD with A group and the control group ( $\mathrm{p}=0.0001, \mathrm{p}=0.0001$, respectively) but no difference between the PD group without $A$ and the control group $(p=1.00)$. Table 2 presents the two-way and three-way comparisons of the PD group with and without A and the control group for oxidative and antioxidative stress parameters.

Comparison of the patient and control groups for HDRS and HARS scores showed statistically higher HDRS and HARS scores in the patient group ( $\mathrm{p}=0.0001, \mathrm{p}=0.0001$, respectively).

Comparison of the with A and without A groups by the scale scores and weekly number of attacks revealed that the group with A had a statistically significantly higher number of attacks and PAS total and HARS scores $(\mathrm{p}=0.06, \mathrm{p}=0.0001$, $\mathrm{p}=0.04$, respectively). There was no significant difference between the HDRS scores ( $\mathrm{p}=0.54$ ).

When we evaluated the relationship between the clinical variables (age, number of attacks, PAS, HDRS, HARS), oxidative stress parameter (MDA) and antioxidants (TAC, PON, ARE) with the Multiple Linear Regression Analysis, we saw that the clinical changes did not have a significant effect on oxidative stress parameter (MDA) and antioxidants (TAC, PON, $\mathrm{ARE}$ ) in the $\mathrm{PB}$ with $\mathrm{A}$ and $\mathrm{PB}$ without $\mathrm{A}$ groups ( $\mathrm{p} \geq 0.05)$ (Table 3-10). When we evaluated the relationship between $A$, oxidative stress parameters (MDA) and antioxidants (TAC, PON, ARE) with the Multiple Linear Regression Analysis, we saw that the A had a significant effect on antioxidants (TAC, $\mathrm{ARE})$ and oxidative stress parameter (MDA) $(\mathrm{p}=0.02, \mathrm{p}=0.04$, $\mathrm{p}=0.001$, respectively) (Table 11 ).

Evaluating the relationship between the oxidative stress parameter (MDA) and antioxidants (TAC, PON, ARE) with each other and the other variables (number of attacks, PAS total, HDRS, HARS) showed a negative relation between the TAC level and the MDA, PAS total, HARS and number of attacks $(\mathrm{p}<0.05)$. There was a positive relationship between PON and ARE, and a negative relationship between PON and MDA, PAS total, HDRS, HARS and the number of attacks $(\mathrm{p}<0.05)$. There was a negative correlation between ARE and MDA, the

Table 3. Evaluation of the effect of clinical variables on the TAC antioxidant parameter with multiple linear regression analysis in the PD with A group

\begin{tabular}{clccccc}
\hline Model & \multicolumn{1}{c}{ Variable } & $\mathrm{B}$ & $\mathrm{SE}_{\beta}$ & $\beta$ & $\mathrm{t}$ & $\mathrm{p}$ \\
\hline 1 & Constant & 1.550 & 0.837 & - & 0.08 & 0.851 \\
& Age & 0.002 & 0.004 & 0.092 & 0.428 & 0.67 \\
& Number of attacks & -0.007 & 0.018 & -0.085 & -0.381 & 0.71 \\
& PAS & -0.001 & 0.027 & -0.010 & -0.041 & 0.97 \\
& HDRS & 0.019 & 0.028 & 0.147 & 0.674 & 0.51 \\
& HARS & 0.0001 & 0.017 & -0.003 & -0.011 & 0.99 \\
\hline
\end{tabular}

PAS Total: Panic and Agoraphobia Scale, HDRS: Hamilton Depression Rating Scale, HARS: Hamilton Anxiety Rating Scale, TAC: total antioxidat capacity, PD: panic disorder

Table 4. Evaluation of the effect of clinical variables on the PON antioxidant parameter with multiple linear regression analysis in the PD with A group

\begin{tabular}{clrrrrr}
\hline Model & \multicolumn{1}{c}{ Variable } & \multicolumn{1}{c}{$\mathrm{B}$} & \multicolumn{1}{c}{$\mathrm{SE}_{\beta}$} & $\mathrm{s}$ & $\mathrm{t}$ \\
\hline \multirow{2}{*}{1} & Constant & 167.622 & 174.740 & - & 0.959 & 0.35 \\
& Age & 0.606 & 0.859 & 0.149 & 0.706 & 0.49 \\
& Number of attacks & 1.142 & 3.658 & 0.068 & 0.312 & 0.76 \\
& PAS & -3.110 & 5.580 & -0.132 & -0.557 & 0.58 \\
& HDRS & -2.802 & 5.912 & -0.102 & -0.474 & 0.64 \\
& HARS & -2.188 & 3.527 & -0.154 & -0.620 & 0.54 \\
\hline
\end{tabular}

PAS Total: Panic and Agoraphobia Scale, HDRS: Hamilton Depression Rating Scale, HARS: Hamilton Anxiety Rating Scale, PD: panic disorder, PON: paraoxonase 
number of attacks and PAS total $(\mathrm{p}<0.05)$. There was a negative relationship between MDA and TAC, PON, and ARE, and a negative relationship between MDA and the number of attacks and PAS total $(\mathrm{p}<0.05)$. There was a significant positive relationship between the PAS total and HDRS, HARS and number of attacks $(\mathrm{p}<0.05)$. Table 12 present the rela-

Table 5. Evaluation of the effect of clinical variables on the ARE antioxidant parameter with multiple linear regression analysis in the PD with A group

\begin{tabular}{clccccc}
\hline Model & \multicolumn{1}{c}{ Variable } & $\mathrm{B}$ & $\mathrm{SE}$ & $\beta$ & $\mathrm{t}$ & $\mathrm{p}$ \\
\hline \multirow{2}{*}{1} & Constant & 79.266 & 29.873 & - & 2.653 & $0.01^{*}$ \\
& Age & 0.020 & 0.147 & 0.027 & 0.134 & 0.89 \\
& Number of attacks & 1.215 & 0.625 & 0.403 & 1.943 & 0.06 \\
& PAS & -0.036 & 0.954 & -0.008 & -0.038 & 0.97 \\
& HDRS & 0.120 & 1.011 & 0.024 & 0.119 & 0.91 \\
& HARS & 0.044 & 0.603 & 0.017 & 0.073 & 0.94 \\
\hline
\end{tabular}

${ }^{*} \mathrm{p}<0.05$. PAS Total: Panic and Agoraphobia Scale, HDRS: Hamilton Depression Rating Scale, HARS: Hamilton Anxiety Rating Scale, PD: panic disorder, ARE: arylesterase

Table 6. Evaluation of the effect of clinical variables on the MDA oxidant parameter with multiple linear regression analysis in the PD with A group

\begin{tabular}{clccccc}
\hline Model & \multicolumn{1}{c}{ Variable } & $\mathrm{B}$ & $\mathrm{SE}$ & $\beta$ & $\mathrm{t}$ & $\mathrm{p}$ \\
\hline 1 & Constant & -1.183 & 3.503 & - & -0.338 & 0.74 \\
& Age & -0.015 & 0.017 & -0.174 & -0.885 & 0.38 \\
& Number of attacks & 0.015 & 0.073 & 0.041 & 0.203 & 0.84 \\
& PAS & 0.187 & 0.112 & 0.368 & 1.669 & 0.11 \\
& HDRS & -0.108 & 0.119 & -0.180 & -0.908 & 0.37 \\
& HARS & -0.015 & 0.071 & -0.049 & -0.210 & 0.83 \\
\hline
\end{tabular}

PAS Total: Panic and Agoraphobia Scale, HDRS: Hamilton Depression Rating Scale, HARS: Hamilton Anxiety Rating Scale, PD: panic disorder, MDA: malondialdehyde

Table 7. Evaluation of the effect of clinical variables on the TAC antioxidant parameter with multiple linear regression analysis in the PD without A group

\begin{tabular}{clccccc}
\hline Model & \multicolumn{1}{c}{ Variable } & $\mathrm{B}$ & $\mathrm{SE}_{\beta}$ & $\beta$ & $\mathrm{t}$ & $\mathrm{p}$ \\
\hline 1 & Constant & 1.728 & 0.600 & - & 2.879 & $0.01^{*}$ \\
& Age & 0.005 & 0.004 & 0.284 & 1.106 & 0.28 \\
& Number of attacks & 0.001 & 0.025 & 0.014 & 0.059 & 0.95 \\
& PAS & 0.007 & 0.015 & 0.108 & 0.424 & 0.68 \\
& HDRS & 0.021 & 0.040 & 0.143 & 0.532 & 0.60 \\
& HARS & -0.044 & 0.028 & -0.408 & -1.553 & 0.14 \\
\hline
\end{tabular}

${ }^{*} \mathrm{p}<0.05$. PAS Total: Panic and Agoraphobia Scale, HDRS: Hamilton Depression Rating Scale, HARS: Hamilton Anxiety Rating Scale, PD: panic disorder, TAC: total antioxidat capacity

Table 8. Evaluation of the effect of clinical variables on the PON antioxidant parameter with multiple linear regression analysis in the PD without A group

\begin{tabular}{clrrrrr}
\hline Model & \multicolumn{1}{c}{ Variable } & \multicolumn{1}{c}{$\mathrm{B}$} & \multicolumn{1}{c}{$\mathrm{SE} \mathrm{B}_{\beta}$} & $\mathrm{t}$ & $\mathrm{p}$ \\
\hline \multirow{2}{*}{1} & Constant & 244.039 & 175.956 & - & 1.387 & 0.18 \\
& Age & 0.505 & 1.255 & 0.110 & 0.402 & 0.69 \\
& Number of attacks & -4.846 & 7.181 & -0.173 & -0.675 & 0.51 \\
& PAS & -4.160 & 4.526 & -0.249 & -0.919 & 0.37 \\
& HDRS & -12.068 & 11.661 & -0.296 & -1.035 & 0.32 \\
& HARS & 3.278 & 8.221 & 0.111 & 0.399 & 0.69 \\
\hline
\end{tabular}

PAS Total: Panic and Agoraphobia Scale, HDRS: Hamilton Depression Rating Scale, HARS: Hamilton Anxiety Rating Scale, PD: panic disorder, PON: paraoxonase 
tionship between the oxidative stress parameter (MDA) and antioxidants (TAC, PON, ARE) both with each other and with the weekly number of panic attacks, PAS total, HDRS, and HARS scores.

\section{DISCUSSION}

We found statistically significantly lower TAC, PON and ARE levels and higher MDA levels in the PD patients compared to the control group. Comparison of the three groups of PD with A, PD without A and the control group showed a significant difference for TAC, PON, ARE antioxidants and the MDA oxidant while it was the 'with A' subgroup that created this difference between the patient group and the control group. These findings indicate that oxidative/anti-oxidative mechanisms may play an important role in the pathogenesis of PD with A.

The few studies on patients with a diagnosis of PD have reported a wide range of results. Kuloglu et al. ${ }^{17}$ have compared glutathione peroxidase (GPx), catalase (CAT), superoxide dismutase (SOD) antioxidants and the MDA oxidant in $20 \mathrm{PD}$ patients and 20 healthy control subjects and found the GPx, SOD and MDA levels to be significantly higher in the PD group. Ersoy et al. ${ }^{19}$ investigated the TAC and ceruloplasmin levels in 19 PD patients and 40 healthy control group subjects and found both parameters to be higher in the PD group. Herken et al. compared the oxidant xanthine oxidase (XO) and nitric oxide (NO) levels between 32 PD patients and 20

Table 9. Evaluation of the effect of clinical variables on the ARE antioxidant parameter with multiple linear regression analysis in the PD without A group

\begin{tabular}{clccccc}
\hline Model & \multicolumn{1}{c}{ Variable } & $\mathrm{B}$ & $\mathrm{SE}_{\beta}$ & $\beta$ & $\mathrm{t}$ & $\mathrm{p}$ \\
\hline \multirow{2}{*}{1} & Constant & 99.080 & 28.026 & - & 3.178 & $0.006^{*}$ \\
& Age & -0.069 & 0.200 & -0.095 & -0.346 & 0.73 \\
& Number of attacks & 0.443 & 1.144 & 0.100 & 0.387 & 0.70 \\
& PAS & -0.310 & 0.721 & -0.117 & -0.430 & 0.67 \\
& HDRS & 0.797 & 1.857 & 0.123 & 0.429 & 0.67 \\
& HARS & 0.875 & 1.309 & 0.187 & 0.668 & 0.51 \\
\hline
\end{tabular}

${ }^{*} \mathrm{p}<0.05$. PAS Total: Panic and Agoraphobia Scale, HDRS: Hamilton Depression Rating Scale, HARS: Hamilton Anxiety Rating Scale, PD: panic disorder, ARE: arylesterase

Table 10. Evaluation of the effect of clinical variables on the MDA oxidant parameter with multiple linear regression analysis in the PD without A group

\begin{tabular}{clccccc}
\hline Model & \multicolumn{1}{c}{ Variable } & $\mathrm{B}$ & $\mathrm{SE}_{\beta}$ & $\beta$ & $\mathrm{t}$ & $\mathrm{p}$ \\
\hline 1 & Constant & 1.912 & 1.155 & - & 1.655 & 0.12 \\
& Age & -0.003 & 0.008 & -0.081 & -0.319 & 0.75 \\
& Number of attacks & -0.051 & 0.047 & -0.259 & -1.088 & 0.29 \\
& PAS & 0.021 & 0.030 & 0.179 & 0,714 & -1.261 \\
& HDRS & -0.097 & 0.077 & -0.335 & 0.22 & 0.15 \\
\hline
\end{tabular}

PAS Total: Panic and Agoraphobia Scale, HDRS: Hamilton Depression Rating Scale, HARS: Hamilton Anxiety Rating Scale, PD: panic disorder, MDA: malondialdehyde

Table 11. Evaluation of the effect of A on the TAC, PON, ARE antioxidant parameters and MDA oxidant parameter with multiple linear regression analysis

\begin{tabular}{clccccc}
\hline & Variable & $\mathrm{B}$ & $\mathrm{SE}$ & $\beta$ & $\mathrm{t}$ & $\mathrm{p}$ \\
\hline \multirow{2}{*}{ TAC } & Constant & 1.790 & 0.042 & - & 42.571 & 0.0001 \\
& Agorophobia & -0.127 & 0.056 & -0.303 & -2.272 & $0.02^{*}$ \\
\multirow{3}{*}{ PON } & Constant & 78.261 & 9.741 & - & 8.034 & 0.0001 \\
& Agorophobia & -18.394 & 12.947 & -0.195 & -1.421 & 0.16 \\
& Constant & 96.174 & 1.660 & - & 57.942 & 0.0001 \\
& Agorophobia & -4.474 & 2.206 & -0.273 & -2.028 & $0.04^{*}$ \\
& Constant & 2.163 & 0.170 & - & 12.755 & 0.0001 \\
& Agorophobia & 0.820 & 0.225 & 0.454 & 3.640 & $0.001^{*}$ \\
\hline
\end{tabular}

${ }^{*} \mathrm{p}<0.05$. TAC: total antioxidant capacity, PON: paraoxonase, ARE: arylesterase, MDA: malondialdehyde 
Table 12. The relationship between the oxidative stress parameter (MDA) and antioxidants (TAC, PON, ARE) both with each other and with the weekly number of panic attacks, PAS total, HDRS, and HARS scores

\begin{tabular}{|c|c|c|c|c|}
\hline & TAC & PON & ARE & MDA \\
\hline & $(\mathrm{r}, \mathrm{p})$ & $(\mathrm{r}, \mathrm{p})$ & $(\mathrm{r}, \mathrm{p})$ & $(\mathrm{r}, \mathrm{p})$ \\
\hline TAC & & $(0.17,0.07)$ & $(0.08,0.39)$ & $\left(-0.23,0.01^{*}\right)$ \\
\hline PON & $(0.17,0.07)$ & & $\left(0.47,0.0001^{*}\right)$ & $\left(-0.22,0.02^{*}\right)$ \\
\hline ARE & $(0.08,0.39)$ & $\left(0.47,0.0001^{*}\right)$ & & $\left(-0.34,0.0001^{*}\right)$ \\
\hline MDA & $\left(-0.23,0.01^{*}\right)$ & $\left(-0.22,0.02^{*}\right)$ & $\left(-0.34,0.0001^{*}\right)$ & \\
\hline Number of attacks & $\left(-0.27,0.005^{*}\right)$ & $\left(-0.34,0.0001^{*}\right)$ & $\left(-0.19,0.04^{*}\right)$ & $\left(0.40,0.0001^{*}\right)$ \\
\hline PAS total & $\left(-0.24,0.01^{*}\right)$ & $\left(-0.34,0.0001^{*}\right)$ & $\left(-0.23,0.01^{*}\right)$ & $\left(0.36,0.0001^{*}\right)$ \\
\hline HDRS & $(-0.14,0.13)$ & $\left(-0.29,0.002^{*}\right)$ & $(-0.12,0.20)$ & $(0.11,0.22)$ \\
\hline HARS & $\left(-0.23,0.01^{*}\right)$ & $\left(-0.27,0.005^{*}\right)$ & $(-0.12,0.20)$ & $(0.16,0.09)$ \\
\hline
\end{tabular}

${ }^{*} \mathrm{p}<0.05$. TAC: total antioxidant capacity, PON: paraoxonase, ARE: arylesterase, MDA: malondialdehyde, PAS Total: Panic and Agoraphobia Scale, HDRS: Hamilton Depression Rating Scale, HARS: Hamilton Anxiety Rating Scale

healthy subjects in the control group and found XO oxidant levels to be higher in the patient group than the control group. The same study found no significant difference between the SOD and NO scores. ${ }^{18}$ We found the MDA oxidant level to be high in the PD group in our study, similar to these studies, but the TAC, PON and ARE anti-oxidative parameter levels were low in contrast. These results can be interpreted as the presence of a damaged anti-oxidative system together with increased oxidative stress. Furthermore, it could be said that A is more effective on oxidative stress and the damage in anti-oxidative mechanisms as the PON, ARE and TAC antioxidant parameters were lower but the MDA oxidant higher in the PD with A subgroup compared to the control group while the same parameters were no different than the control group in the PD group without $\mathrm{A}$.

A has been reported to increase the severity of the disorder in many studies. ${ }^{23-25}$ A study on the pituitary volume in $\mathrm{PD}$ has shown the pituitary volume to be much smaller in $\mathrm{PD}$ patients with A compared to those without. The same study found a negative relationship between PD severity and pituitary volume. ${ }^{26}$ Another study that used Single-Positron Emission Tomography (SPECT) to evaluate regional cerebral blood flow in PD showed that there was a statistically significant decrease in blood flow in the right occipital region and an increased blood flow in the right superior temporal region in the PD with A patients compared to those without $A \cdot{ }^{27}$ All these findings make it possible to comment that besides the diagnostic separation regarding whether $\mathrm{PD}$ is accompanied by $\mathrm{A}$ or not, there may be differences in the biological structures and physiopathology of the two groups. Our study has shown that oxidative stress increase and damage appears in the antioxidative defense mechanisms in the presence of A. It may therefore be necessary to evaluate $\mathrm{A}$ as a separate disorder other than a problem increasing the severity of $\mathrm{PD}$. The definition of A has been changed into a disorder with its own code whether PD is present or not in DSM-V that is currently being prepared. It is said that this hypothesis is supported by familial genetic data, previous psychiatric history, concurrent diagnosis patterns, disease course, response to treatment and safety evaluations. ${ }^{28}$ Evaluation of A in addition to PD for oxidative stress and antioxidant systems in our study supports this change in the DSM-V.

These studies increase the evidence showing that there may be antioxidant enzyme metabolism changes in PD patients. It has even been suggested that the oxidative stress and antioxidant systems can be used as diagnostic and prognostic devices in PD and could be useful to monitor drug efficacy. ${ }^{17,18}$ We showed in this study that the antioxidant parameters decreased compared to the control group in PD and that this was derived from the A subgroup, in contrast to some other studies. This finding may indicate a role for damaged anti-oxidative defense mechanisms in the etiopathogenesis of PD with A. However, we believe that it would be best to discuss at this point whether the increased oxidative stress and damaged antioxidant systems are a part of the pathophysiology and etiology of the disease or a reflection of the abnormal cerebral function.

Comparison of the scale (HDRS, HARS) scores between the $\mathrm{PD}$ and control groups revealed that the patients had statistically significantly higher HDRS and HARS scores that the control group. The presence of a concurrent diagnosis was an exclusion criterion in our study but the higher scale scores in the PD group compared to the healthy controls may indicate a relationship with expectation anxiety, a natural manifestation of the disorder, and concurrent sub-threshold anxiety disorders. Comparison of the PD subgroups of with and without A for number of attacks and the scales (PAS total, HDRS, HARS) showed that the number of attacks, PAS total and HARS scores were statistically significantly higher in the group with $\mathrm{A}$ than the group without. There was no significant 
difference between HDRS scores. A study evaluating the quality of life in PD reported that the group with A had more pronounced disturbance of their social, professional and family life, higher scores for scales such as PAS total and HARS, a higher number of attacks and a more pronounced disruption of the quality of life in general..$^{24}$ These results are consistent with the results of our study.

Oxidative stress is known to increase in mayn systemic disorders such as diabetes mellitus, hypertension and osteoarthritis and in neuropsychiatric disorders. Oxidative and antioxidative parameters have also been shown to be unstable markers and to be influenced by many factors such as smoking, alcohol, excessive exercise, advanced age, medication usage and air pollution. ${ }^{29-31}$ We chose our exclusion criteria taking these factors into account when creating our patient and control groups. The regression analysis we performed to determine the effect of A and clinical variables such as age, weekly number of panic attacks, PAS total, HDRS, and HARS on the TAC, PON, ARE antioxidants and the MDA oxidant showed that these clinical variables did not have a significant effect on oxidative and antioxidative parameters. As for A, we saw that the it has a significant effect on antioxidants (TAC, ARE) and oxidative stress parameter (MDA). These results support our findings that the addition of PD to A increases oxidative stress and antioxidative mechanism damage. Other studies in PB on this subject have not focused on factors influencing oxidative and antioxidative markers, increasing the importance of our study. ${ }^{17-20}$

Evaluation of the relationship between the oxidative antioxidative parameters between themselves and with each other shows a negative relationship between MDA levels and the TAC, PON, ARE levels with the oxidative parameters increasing while the anti-oxidative parameters decrease in PD. The presence of a negative relationship between the number of attacks, PAS total and HARS scores and the TAC, PON, ARE levels, but a positive relationship between the MDA levels indicate that antioxidants decrease and oxidants increase as disease severity increases. Evaluating our study results in light of this information could lead to an interpretation that the oxidative stress increases but the anti-oxidative mechanisms are adequate in coping with this stress at the beginning of the disease but the anti-oxidative defense mechanisms become disrupted with increasing damage and therefore cannot respond to the stress. Similarly, we saw that the high oxidative stress in the PD without A group in our study became more pronounced with the addition of $A$ and the anti-oxidative mechanisms become inadequate in fighting off this stress. Variables that indicate an increased PD severity such as increased number of attacks and high PAS and HARS scores further increase the already high level of oxidative stress and damage in anti- oxidative mechanisms seen in PD. Taking these results into account, new studies on the roles of oxidative/anti-oxidative mechanisms in agoraphobic patients without PD are needed. One limitation of our study is having one oxidant investigated against three oxidant parameters. Another limitation is the small sample size and we could also have made another group from A patients without PB. In conclusion, new studies with larger and control groups are needed to fully elucidate oxidative and antioxidative mechanisms of PD.

Taking into account all literature studies on oxidative/antioxidative mechanisms, the causality relationship between psychiatric disorders and increased levels of oxidants is not clear. It is not known for sure whether the increased oxidants cause psychiatric disorders or the reverse is true. It is therefore necessary to understand oxidative stress mechanisms in psychiatric disorders to possibly have a better understanding of the disease activity and response to treatment using oxidative/anti-oxidative markers, to pinpoint the etiology and to increase treatment options.

\section{Acknowledgments}

This study was supported by Inonu University Scientific Research Project Unit.

\section{REFERENCES}

1. American Psychiatric Association. Diagnostic and Statistical Manual of Mental Disorders, 4th Edition. Washington, DC: American Psychiatric Association; 1994.

2. Pine DS, McClure EB. Anksiyete bozuklukları: Klinik özellikleri. In: Aydin H, Bozkurt A, Editors. Kaplan \& Sadock's Comprehensive Textbook of Psychiatry, 8th Edition. Ankara: Güneş Kitabevi; 2007, p.17681771.

3. Grillon C. Anxiety Disorders. Psychophysiological Aspects. In: Sadock BJ, Sadock VA, Editors. Kaplan \& Sadock's Comprehensive Textbook of Psychiatry, 8th Edition. Philadelphia: Lippincott Williams \& Wilkins, 2005, p.1728-1739.

4. Bayraktar E. Panik bozukluğu ve agorafobi. In: Işık E, Taner E, Işık U, Editors. Güncel Klinik Psikiyatri. Ankara: Golden Print Matbaası; 2008, p.209-222.

5. Yao JK, Reddy R, McElhinny LG, van Kammen DP. Effects of haloperidol on antioxidant defense system enzymes in schizophrenia. J Psychiatr Res 1998;32:385-391.

6. Khan MM, Evans DR, Gunna V, Scheffer RE, Parikh VV, Mahadik SP. Reduced erythrocyte membrane essential fatty acids and increased lipid peroxides in schizophrenia at the never-medicated fist-episode of psychosis and after years of treatment with antipsychotics. Schizophr Res 2002;58:1-10.

7. Savas HA, Gergerlioglu HS, Armutcu F, Herken H, Yilmaz HR, Kocoglu E, et al. Elevated serum nitric oxide and superoxide dismutase in euthymic bipolar patients: impact of past episodes. World J Biol Psychiatry 2006;7:51-55.

8. Zhang XY, Tan YL, Cao LY, Wu GY, Xu Q, Shen Y, et al. Antioxidant enzymes and lipid peroxidation in different forms of schizophrenia treated with typical and atypical antipsychotics. Schizophr Res 2006; 81:291-300.

9. Bulut M, Selek S, Gergerlioglu HS, Savas HA, Yilmaz HR, Yuce M, et al. Malondialdehyde levels in adult attention-deficit hyperactivity disorder. J Psychiatry Neurosci 2007;32:435-438. 
10. Machado-Vieira R, Andreazza AC, Viale CI, Zanatto V, Cereser V Jr, da Silva Vargas R, et al. Oxidative stress parameters in unmedicated and treated bipolar subjects during initial manic episode: a possible role for lithium antioxidant effects. Neurosci Lett 2007;421:33-36.

11. Kehrer JP, Smith CV. Free Radicals in Biology: Sources, Reactivities, and Roles in the Etiology of Human Diseases. In: Frei B, Editor. Natural Antioxidants in Human Health and Disease. San Diego: Academic Press; 1994, p.25-62.

12. Halliwell B. Oxidative stress, nutrition and health. Experimental strategies for optimization of nutritional antioxidant intake in humans. Free Radic Res 1996;25:57-74.

13. Betteridge DJ. What is oxidative stress? Metabolism 2000;49:3-8.

14. Niki E, Yoshida Y, Saito Y, Noguchi N. Lipid peroxidation: mechanisms, inhibition, and biological effects. Biochem Biophys Res Commun 2005; 338:668-676.

15. Seven A, Candan G. Serbest radikaller ve lipid peroksidasyonu. Klinik Gelişim 1995;8:3906-3911.

16. Ng F, Berk M, Dean O, Bush AI. Oxidative stress in psychiatric disorders: evidence base and therapeutic implications. Int J Neuropsychopharmcol 2008;11:851-876.

17. Kuloglu M, Atmaca M, Tezcan E, Ustundag B, Bulut S. Antioxidant enzyme and malondialdehyde levels in patients with panic disorder. Neuropsychobiology 2002;46:186-189.

18. Herken H, Akyol O, Yilmaz HR, Tutkun H, Savas HA, Ozen ME, et al. Nitric Oxide, Adenosine deaminase, xanthine oxidase and superoxide dismutase in patients with panic disorder: alterations by antidepressan treatment. Hum Psychopharmacol 2006;21:53-59.

19. Ersoy MA, Selek S, Celik H, Erel O, Kaya MC, Savas HA, et al. Role of oxidative parameters in etiopathogenesis and prognosis of panic disor- der. Int J Neurosci 2008;118:1025-1037.

20. Yarpuz AY, Yılmaz A, Soykan A, Elgün S, Kumbasar H. Panik bozukluğunda adenozin deaminaz ve dipeptidil peptidaz IV enzim düzeyleri. Türk Psikiyatri Derg 2008;9:149-156.

21. Erel O. A novel automated method to measure total antioxidant response against potent free radical reactions. Clin Biochem 2004;37: 112-119.

22. Ohkawa H, Ohishi N, Yagi K. Assay of lipid peroxides in animal tissue by thiobarbutiric acid reaction. Anal Biochem1979;95:351-358.

23. Tükel R. Panik bozukluğu. Psikiyatri Dünyası 1997;1:12-17.

24. Eaton WW, Anthony JC, Romanoski A, Tien A, Gallo J, Cai G, et al. Onset and recovery from panic disorder in the Baltimore Epidemiologic Catchment Area follow-up. Br J Psychiatry 1998;173:501-507.

25. Altıntaş EY. Panik Bozuklukta Yaşam Kalitesi: 3 Aylık İzlem Çalışması. Uzmanlık Tezi. Adana: Çukurova Üniversitesi; 2006.

26. Kartalci S, Dogan M, Unal S, Ozcan AC, Ozdemir S, Atmaca M. Pituitary volume in patients with panic disorder. Prog Neuropsychopharmacol Biol Psychiatry 2011;35:203-207.

27. Eren İ, Tükel R, Polat A, Karaman R, Ünal S. Panik bozukluğunda bölgesel kan akımı değişikliklerinin Tc99m-HMPAO SPECT ile değerlendirilmesi. Türk Psikiyatri Derg 2002;13:89-97.

28. Şar V. DSM-5 Taslak Tanı Ölçütlerine Genel Bir Bakış: "Batı Cephesinde Yeni Bir Şey Yok’mu? Klin Psikiyatr Derg 2010;13:196-208.

29. Pham-Huy LA, He H, Pham-Huy C. Free radicals, antioxidants in disease and health. Int J Biomed Sci 2008;4:89-96.

30. Halliwell B. Free radicals and other reactive species in disease. Encyclopedia of Life Sciences 2005;5:1-7.

31. Shinde A, Ganu J, Naik P. Effect of Free Radicals \& Antioxidants on Oxidative Stress: A Review. J Dental \& Allied Sciences 2012;1:63-66. 